\title{
Speed Sensorless Control of Six-Phase Asynchronous Motor Drive
}

\author{
Z.M.S. Elbarbary \\ Faculty of Engineering - KFS University \\ z_elbarbary@yahoo.com
}

\begin{abstract}
Multi -phase ac motor drives are nowadays considered for various applications, due to many advantages that they offer when compared to threephase motors. Cancellation of mechanical position or speed sensors at the motor shaft have the attractions for adjustable speed drives of induction motor to reduce the cost and increase the reliability. To replace the sensor, information of the rotor speed is extracted from measured stator currents and voltages at motor terminals. This paper investigates speed estimation method using model reference adaptive system (MRAS) to improve the performance of a sensorless vector controller of six-phase induction motor (IM). In the proposed method, the stator current is used as the state variable to estimate the speed. Since the stator current error is represented as a function of the first degree for the error value in the speed estimation, the proposed method provides fast speed estimation and is also, more robust to variations in the stator resistance, compared with other MRAS methods. Consequently, this method can improve the performance of a sensorless vector controller in a low speed region and at zero-speed. The proposed method is verified by simulation using the Matlab/Simulink package. The performance of the proposed system is investigated at different operating conditions. The proposed controller is robust and suitable for high performance six-phase induction motor drives. Simulation results validate the proposed approaches.
\end{abstract}

Keywords- Six-phase induction motor, speed sensorless control, field oriented control

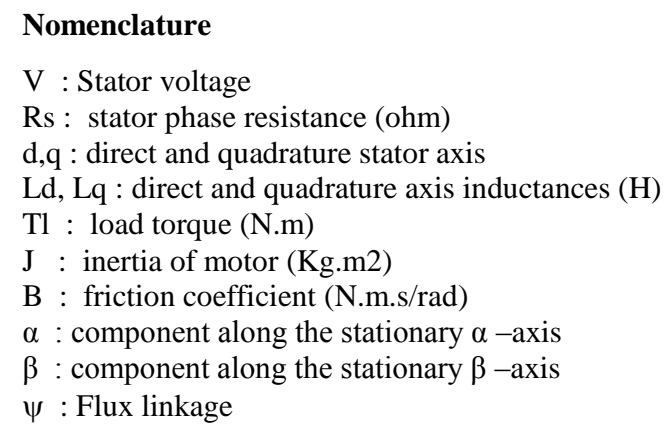

\section{INTRODUCTION}

Multi-phase induction motor offer several advantages compared to conventional three-phase motor. Some of the advantages are reducing the amplitude and increasing the frequency of torque pulsations, reducing the rotor current harmonics, reducing the stator current per phase without increasing the voltage per phase, This allows the requirements for capacity of the motor and inverter semiconductor elements to be reduced. lowering the dc link current harmonics, fault tolerance, reduced power switch rating etc. By increasing the number of phases it is also possible to increase the power/torque per rms ampere for the same volume machine. Multiphase induction motors allow greater reliability of the drive systems to be ensured because they may be conditionally operated at failure of one or more stator phases. Applications involving high power may require multiphase systems, in order to reduce stress on the switching devices. [1-7].

In many publications about position and sensorless control methods of the multiphase induction motors. Most researches are based on the Field-Oriented Control and Direct Torque Control,[8-13] .Each method presents its respective advantages and disadvantages. Both, Extended Kalman Filter (EKF) [14], and Model Reference Adaptive System (MRAS) [15-20], based methods give robust speed and flux estimates but they are complex in implementation. Sliding mode observers [21] is used to estimate rotor flux, rotor time constant and motor speed. These observers have robustness and parameter insensitivity. But, they need fast execution and high switching rate. To overcome the disadvantages associated with above model-based schemes, machine saliency and high frequency voltage signal injection have been used . They increase the complexity of the system and require a high precision measurement. In other publication a hybrid between two different schemes . All these methods aim to achieve parametric robustness and wide range of speed estimation.

In this paper, an indirect rotor field oriented based speed estimation using model reference adaptive system (MRAS) control for high performance induction motor drive is proposed. The proposed method can provide fast speed estimation and is also more robust to variations in the stator resistance. The proposed MRAS method improves the performance of a sensorless vector controller in a low speed region and at zero-speed. The effectiveness of the proposed method is tested at different operating conditions. Simulation results are presented and discussed. The paper is organized as follows, section II presents the description of mathematical model of the system under study. In section III, the proposed MRAS speed estimation technique is introduced. The simulation results are explained in section IV and finally section $\mathrm{V}$ introduced the results discussion and conclusions 


\section{SYSTEM DESCRIPTION AND MATHEMATICAL MODEL}

The control scheme of six- phase induction motor drive consists of the modelling of the six-phase IM, speed estimation, inverter, and an indirect rotor field oriented control of six-phase IM, which are discussed in the following subsections:

\section{A. Indirect rotor field oriented control}

The theory of indirect field oriented control is applied for the Six-phase induction motor. The application of the vector control scheme to such arrangement is simple, and can provide fast-decoupled control of torque and flux. In Fig.(2), the estimated motor speed, $\omega_{m}$ is compared to a command speed, $\omega^{*}$, and the error signal is processed by the PI controller, to generate the torque-component current command $I_{q}{ }^{*}$. The flux-component current command $I_{d} *$ is calculated according to adopted control strategy. The two current command components are then transformed with the help of rotor position (for angle $\theta_{e}$ ) to six phase current commands $i_{a}, i_{b} i_{c}, i_{d}, i_{e}$ and $i_{f}$ in the stationary reference frame. The torque producing current component is calculated from:

$I_{q S}^{*}=\frac{1}{k_{t}} \frac{\left(\omega_{r}^{*}-\omega_{r}\right)}{\psi_{d r}^{*}}\left(K_{p}+\frac{K_{I}}{S}\right)$

$I_{d s}^{e^{\star}}=\frac{1}{I_{m}}\left(1+\tau_{r} * p\right) \psi_{d r}^{e^{*}}$

The angular slip frequency command $\left(\omega_{s l}^{*}\right)$ is:

$$
\omega_{s]}^{*}=\frac{I_{m}}{\tau_{r}^{*}} \cdot \frac{I_{q s}^{*}}{\psi_{d r}^{*}}
$$

Where, $\tau_{r}$ is the rotor time constant and $\psi_{d r}^{*}$ is the direct-axis rotor flux. The angular frequency is obtained as follows,

$$
\begin{aligned}
& \omega_{e}^{*}=\omega_{s l}^{*}+\omega_{r} \\
& \theta_{e}^{*}=\int \omega_{e}^{*} \cdot d t \\
& \text { a) } T_{e}=K_{t}\left|\psi_{d r}^{e}\right| I_{q s}^{e}
\end{aligned}
$$

(6)

Equation (6) is similar to that of the separately excited dc motor and denotes that the torque can initially proportional to the quadrature component of the stator current, $I_{q s}^{* e}$, if the $\mathrm{q}^{\mathrm{e}}$-axis component of the flux becomes zero $\left(\mathrm{d}^{\mathrm{e}}\right.$-axis is aligned with the rotor flux axis), and the $\mathrm{d}^{\mathrm{e}}$-axis component $\psi_{\mathrm{dr}}^{\mathrm{e}}$ is kept constant. This is the philosophy of the vector control technique. The axis transformations from rotating to stationary reference frame used for the present work are expressed as follows;

$\left[\begin{array}{c}i_{q s}^{s^{*}} \\ i_{d s}^{s^{*}}\end{array}\right]=\left[\begin{array}{cc}\cos \theta_{s} & \sin \theta_{s} \\ -\sin \theta_{s} & \cos \theta_{s}\end{array}\right]\left[\begin{array}{l}i_{q s}^{e^{*}} \\ i_{d s}^{e^{*}}\end{array}\right]$

where $\theta_{\mathrm{s}}$ represents the sum of the slip and rotor angles.

$$
\left[\begin{array}{c}
i_{a s}^{s^{*}} \\
i_{b s}^{s^{*}} \\
i_{c s}^{s^{*}} \\
i_{d s}^{s^{*}} \\
i_{e s}^{s^{*}} \\
i_{f_{s}^{*}}^{s^{*}}
\end{array}\right]=\left[\begin{array}{cc}
\cos \left(\theta_{S}\right) & \sin \left(\theta_{S}\right) \\
\cos \left(\theta_{S}-\frac{2 \pi}{6}\right) & \sin \left(\theta_{S}-\frac{2 \pi}{6}\right) \\
\cos \left(\theta_{S}-\frac{4 \pi}{6}\right) & \sin \left(\theta_{S}-\frac{4 \pi}{6}\right) \\
\cos \left(\theta_{S}-\frac{6 \pi}{6}\right) & \sin \left(\theta_{S}-\frac{6 \pi}{6}\right) \\
\cos \left(\theta_{S}-\frac{8 \pi}{6}\right) & \sin \left(\theta_{S}-\frac{8 \pi}{6}\right) \\
\cos \left(\theta-\frac{10 \pi}{6}\right) & \sin \left(\theta-\frac{10 \pi}{6}\right)
\end{array}\right]\left[\begin{array}{c}
i_{q s}^{s^{*}} \\
i_{d s}^{s^{*}}
\end{array}\right](8)
$$

These current commands are then compared to the actual motor currents by hysteresis current controller to generate the logic pulses for the six phase inverter switches.

The modulated phase voltages of six-phase inverter fed six-phase induction motor are introduced as a function of switching logic NA, NB, NC,ND,NE and $\mathrm{NF}$ of power switches by the following relations:

$$
\left[\begin{array}{l}
V_{a s} \\
V_{b s} \\
V_{c s} \\
V_{d s} \\
V_{e s} \\
V_{e s}
\end{array}\right]=\frac{V_{d c}}{6}\left[\begin{array}{ccccc}
5 & -1 & -1 & -1 & -1 \\
-1 & 5 & -1 & -1 & -1 \\
-1 & -1 & 5 & -1 & -1 \\
-1 & -1 & -1 & 5 & -1 \\
-1 & -1 & -1 & -1 & 5
\end{array}\right]\left[\begin{array}{c}
N A \\
N B \\
N C \\
N D \\
N E \\
N F
\end{array}\right](9)
$$

The per-phase switching state having a range of $\mathrm{N}=0$ or 1

\section{B. six-phase Induction Motor Model}

Squirrel-cage six-phase induction motor is represented in its $\mathrm{d}-\mathrm{q}$ synchronous reference frame. The winding axes of six-stator winding are displaced by 60 degrees. By increasing the number of phases, it is also possible to increase the torque per ampere for the same machine volume. In this analysis the iron saturation is neglected. The general equations of the six-phase induction motor can be introduced as follows:

The stator voltages equations is given by:

$V_{q s}=R_{s} i_{q s}+\frac{d \psi_{q s}}{d t}+\omega_{r} \psi_{d s}$

$V_{d s}=R_{s} i_{d s}+\frac{d \psi_{d s}}{d t}+\omega_{r} \psi_{q s}$

For the stationary reference frame $\omega=0$, substitute into Equations (1) and (2) yields:

$V_{q s}=R_{s} i_{q s}+\frac{d \psi_{q s}}{d t}$
$V_{d s}=R_{s} i_{d s}+\frac{d \psi_{d s}}{d t}$

The stator linkage is given by:

$\left[\begin{array}{l}\psi_{q s} \\ \psi_{d s}\end{array}\right]=\left[\begin{array}{cccc}0 & L_{s} & 0 & L_{m} \\ L_{s} & 0 & L_{m} & 0\end{array}\right]\left[\begin{array}{l}i_{d s} \\ i_{q s} \\ i_{d r} \\ i_{q r}\end{array}\right]$

Where, $\quad L_{s}=L_{l s}+L_{m}$

The electromagnetic torque is given by: 


$$
\begin{aligned}
& T_{e}=\frac{6}{2} \frac{p}{2}\left(\psi_{d s} I_{q s}-\psi_{q s} I_{d s}\right) \\
& T_{e}-T_{l}=J \frac{d \omega_{r}}{d t}+B \omega_{r}
\end{aligned}
$$

\section{SPEED ESTIMATION BASED ON MRAS}

Estimation of rotor speed based on motor voltage and current instead of using encoder introduced many advantages such as, suitable for hostile environments, including temperature ,Transducer cost avoided ,reduced electrical noise, increased reliability and robustness and fewer maintenance requirements. Model reference adaptive system (MRAS) based Algorithm are one of the best techniques used to estimate the rotor speed of induction motor due to fewer computation requirement compared with other methods and design simplicity.. Model Reference Adaptive Systems (MRAS) techniques are applied in order to estimate rotor speed. This technique is based on the comparison between the outputs of two estimators. The outputs of the two estimators may be rotor flux, back e.m.f., motor reactive power or stator current. The estimator that does not involve the rotor speed $\left(\omega_{\mathrm{r}}\right)$ is considered to be the reference model (voltage model.).And the other model is considered to be the adjustable model (current model). The error between the estimated quantities by the two models is used to drive a suitable adaptation mechanism which generates the estimated rotor speed; $\omega_{\mathrm{r}}$ to be used in the current model was developed. In this paper, the speed observer depends on the MRAS using stator current and rotor flux as state variable[20,21]. This algorithm shown in Figure 1. The stator current is estimated as;

$\frac{d}{d t}\left[\begin{array}{l}\hat{i}_{s \alpha} \\ \hat{i}_{s \beta}\end{array}\right]=\left[\begin{array}{cccc}-a_{1} & 0 & a_{2} & -a_{3} \omega_{r} \\ 0 & -a_{1} & -a_{3} \omega_{r} & a_{2}\end{array}\right]\left[\begin{array}{l}\hat{i}_{s \alpha} \\ \hat{i}_{s \beta} \\ \psi_{s \alpha} \\ \psi_{s \beta}\end{array}\right]+\frac{1}{\delta L_{s}}\left[\begin{array}{l}v_{s \alpha} \\ v_{s \beta}\end{array}\right](18)$

II. WHERE,

$$
\text { III. } \quad D_{1}=1-\left(L_{M} \wedge 2 / L_{S} * L_{R}\right) \text {; }
$$

$\mathbf{A} \mathbf{1}=\left(\mathbf{1} / \mathbf{D}_{\mathbf{1}} * \mathbf{L}_{\mathbf{S}}\right) *(\mathbf{R B a c k a g e}$ Matlab/Simulink [22]

Also, the rotor flux is estimated as follow:

$$
\frac{d}{d t}\left[\begin{array}{l}
\psi_{r \alpha} \\
\psi_{r \beta}
\end{array}\right]=\left[\begin{array}{cccc}
\frac{L_{m}}{T_{r}} & 0 & -\frac{1}{T_{r}} & -\omega_{r} \\
0 & \frac{L_{m}}{T_{r}} & \omega_{r} & -\frac{1}{T_{r}}
\end{array}\right]\left[\begin{array}{c}
i_{s \alpha} \\
i_{s \beta} \\
\psi_{r \alpha} \\
\psi_{r \beta}
\end{array}\right]
$$

The difference in the stator current is obtained as

$$
\left[\begin{array}{c}
\Delta i_{s \alpha} \\
-\Delta i_{s \beta}
\end{array}\right]=\left(\omega_{r}-\hat{\omega}_{r}\right) \frac{T_{r}}{L_{m}}\left[\begin{array}{c}
\psi_{r \alpha} \\
\psi_{r \beta}
\end{array}\right]
$$

Multiplying by the rotor flux and adding them together, we obtain the error of the rotor speed;

$\omega_{r}-\widehat{\omega}_{r}=\left\{\left(i_{s \alpha}-\hat{i}_{s \alpha}\right) \psi_{r \beta}+\left(i_{s \beta}-\hat{i}_{s \beta}\right) \psi_{r \alpha}\right\}$

This error is used to drive PI controller which generates the estimated rotor speed;

$\widehat{\omega}=\left(k_{p}+\frac{k_{I}}{S}\right)\left\{\left(i_{s \alpha}-\hat{i}_{s \alpha}\right) \psi_{r \beta}+\left(i_{s \beta}-\hat{i}_{s \beta}\right) \psi_{r \alpha}\right\}$

This method gives good performance especially at low speed due to absence of derivative operator and, also, it has many advantages like, simple calculations with low computation time ,fast convergence and robustness.

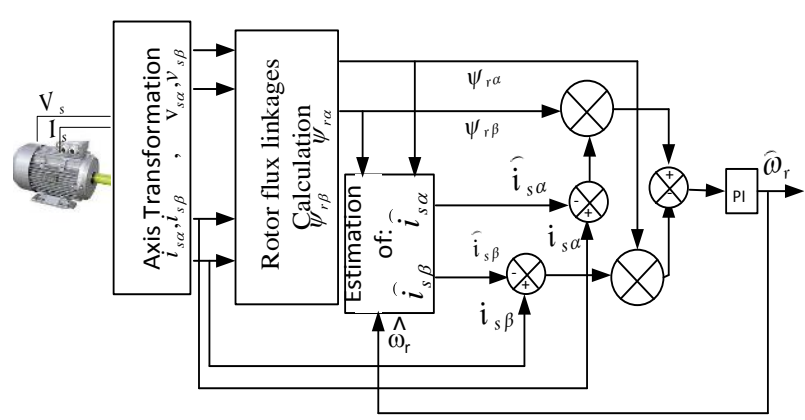

Fig. 1 MRAS speed estimation scheme

\section{SimUlation RESULTS}

The proposed control system shown in Fig. (2) is designed for a simulation investigation. Simulation is carried out using the general purpose simulation $\left.\left.\left(R_{\mathrm{R}} * \mathrm{~L}_{\mathrm{M}} \wedge 2\right) / \mathrm{L}_{\mathrm{R}} \wedge \mathbf{2}\right)\right)$ $\mathrm{a} 2=\left(1 / \mathrm{D}_{1} * \mathrm{~L}_{\mathrm{s}}\right) *\left(\left(\mathrm{R}_{\mathrm{r}} * \mathrm{~L}_{\mathrm{m}}\right) / \mathrm{L}_{\mathrm{r}} \wedge 2\right), \mathrm{a} 3=\left(1 / \mathrm{D}_{1} * \mathrm{~L}_{\mathrm{s}}\right) *\left(\mathrm{~L}_{\mathrm{m}} / \mathrm{L}_{\mathrm{r}}\right)$ and , $\tau_{\mathrm{r}}=\left(\mathrm{L}_{\mathrm{r}} / \mathrm{R}_{\mathrm{r}}\right)$ 


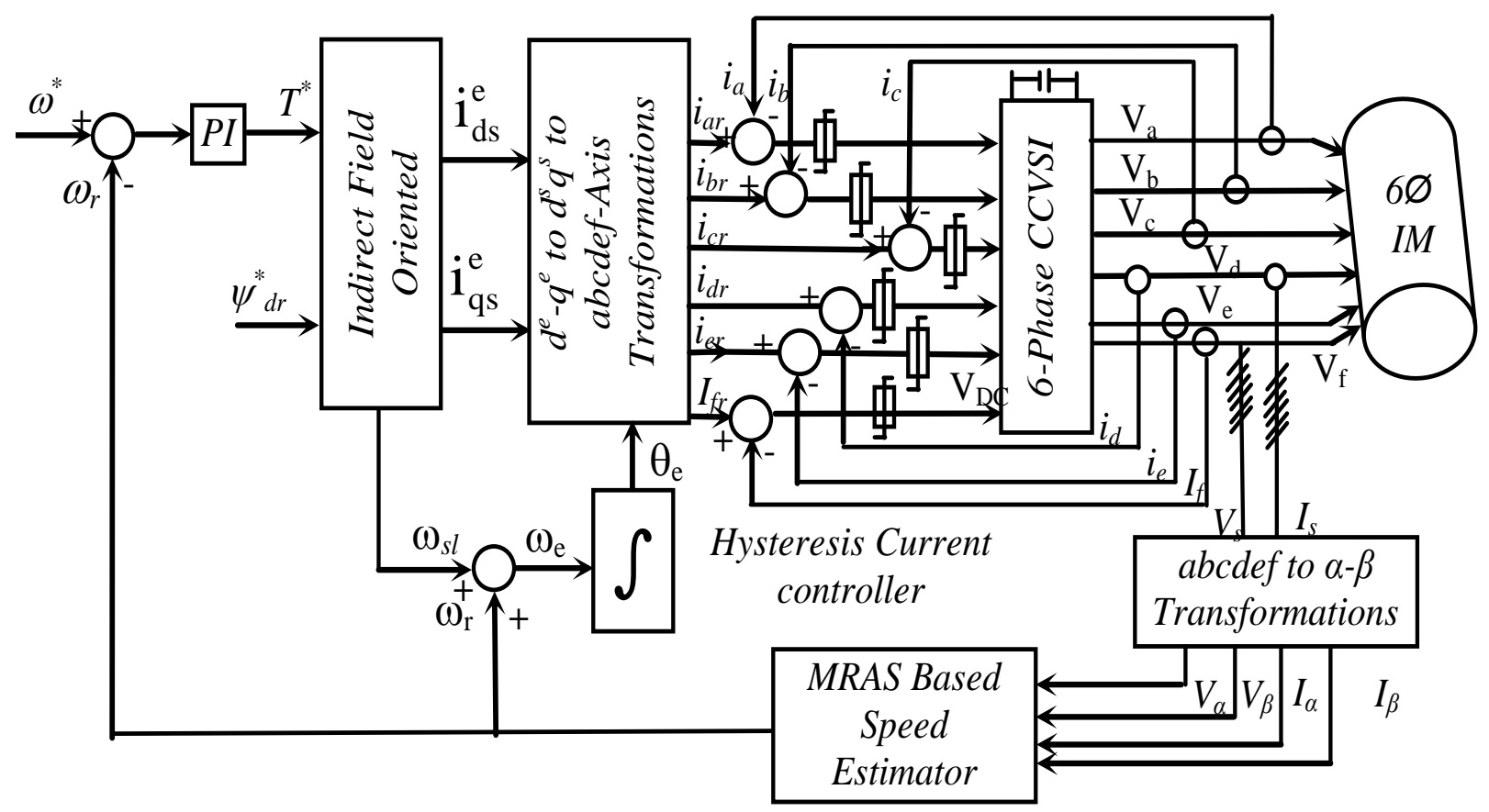

Fig. (2) Block Diagram of the Proposed Speed Control System

Simulation results are presented to show the effectiveness of the proposed scheme at different operating conditions. These results are classified into two categories; the first ensures robustness of the system against stator resistance variation, , while the second represents the dynamic response performance of the system.

\section{CASE 1 : ENSURE THE ROBUSTNESS OF THE SYSTEM TO THE STATOR RESISTANCE VARIATION}

The simulation result for this is illustrated by Figs. 3 and 4 Figure 3.a shows the variation of motor estimated speed from start-up to the steady state speed $(150 \mathrm{rad} / \mathrm{sec})$, which is reached after about $300 \mathrm{~m} \mathrm{sec}$, whereas Figure 3.a shows measured speed signal whares, Fig. $3 b$ shows its estimated corresponding signal These results show a good correlation between the estimated speed signal and its corresponding measured. In the two figures, signals are almost correlated from start-up point up to the steady state value, which is reached after about $300 \mathrm{~m} \mathrm{sec}$. Fig.3.c shows the error between the real motor speed and the estimated one when the stator resistance is $100 \%$ of its nominal value, that is, $5.66 \Omega$, whereas fig.4.d shows the speed error when the stator resistance was increased to $135 \%$, that is, from 5.66 to $7.641 \Omega$. As shown in Fig. $3 \mathrm{c}$ and d, the speed estimation error of the proposed method is constant at $0.5 \mathrm{rad} / \mathrm{sec}$. It's a small value. Hence, the proposed method is robust to stator resistance variation.

To study the estimation algorithm at zero and low speed, the motor is subjected to speed reversal in the speed command to evaluate its the performance. At $\mathrm{t}=1.5$ second the motor speed command is reversal from $150 \mathrm{rad} / \mathrm{sec}$ to $-150 \mathrm{rad} / \mathrm{sec}$. Figure $4 \mathrm{a}$ and $\mathrm{b}$ shows the motor speed signals corresponding to this changes. It can be seen that the motor speed is accelerated smoothly with nearly zero steady state error in both direction. Figure 4.a shows measured speed signals whereas, Figure 4.b shows the estimated speed signal. These results show a good correlation between the estimated speed signal and its corresponding measured during speed reversal. This result is of special interest since it passes the low and zero speed and preserves good speed estimation which verifies the effectiveness of the proposed MRAS to estimate the motor speed. Fig.4.c shows the speed error when the stator resistance was increased to $135 \%$, that is, from 5.66 to $7.641 \Omega$. As shown in Fig. $4 \mathrm{c}$, the speed estimation error of the proposed method is constant at $\pm 0.5 \mathrm{rad} / \mathrm{sec}$ in both direction. This value ensures the robustness of the proposed speed estimation method to stator resistance variation.

\section{Case 2 : Dynamic Performance}

For studying the dynamic performances of proposed system, a series of simulations have been carried out. In this respect, the dynamic response of the proposed speed estimation algorithm is studied under speed step up change under full load condition and load impact.

\section{1-SPEES STEP CHANGE FROM 100 TO 157 (RAD/SEC)}

To study the dynamic response of the control system due to speed step up change, the motor is subjected to speed step up change in the speed command from $100 \mathrm{rad} / \mathrm{sec}$ to $157 \mathrm{rad} / \mathrm{sec}$ At $\mathrm{t}=1.5$ to evaluate its the performances. Figure 5a shows the motor speed signals measured and estimated with speed reference corresponding to this changes. It can be seen that the motor speed signals is accelerated smoothly with nearly zero steady state error . These results show a good correlation between the estimated speed signal and its corresponding measured during 
speed step up change. The motor phase current signals and developed torque corresponding to this speed step up change are shown in Figs. 5b and c respectively.it is noted that the frequency of motor phase currents increases with speed step up and the value of current is constant because the load is constant. Figure $5 \mathrm{~d}$ shows the q-axis stator current it takes the same shape of motor torque where $5 \mathrm{e}$ shows the $\mathrm{d}$-axis stator current it is a constant value. Figure $5 \mathrm{f}$ and $\mathrm{g}$ show $\mathrm{d}$ and $\mathrm{q}$ axis rotor currents. It is noted that the $\mathrm{q}$-axis rotor current equal zero. These results ensure the effectiveness of the proposed system and shows good behaviour with speed step change response.

\section{LOAD IMPACT (CHANGE FROM NO-LOAD TO} 15N.M)

The ability to withstand disturbances in IM control system is another important feature. A step change in the motor load is considered as a typical disturbance. A high performance control system has fast dynamic response in adjusting its control variables so that, the system outputs affected by the load impact will recover to the original status as soon as possible.

the motor is subjected to load impact from no load to $15 \mathrm{Nm}$ at $\mathrm{t}=1$. Sec. Figure $6 \mathrm{a}$ shows the motor speed signals measured and estimated with speed reference corresponding to load impact. It can be seen that the motor speed signals is decelerated and recover to its original value with acceptable time with nearly zero steady state error. These results show a good correlation between the estimated speed signal and its corresponding measured .The motor phase current signals and developed torque corresponding to load are shown in Figs. 5b and c respectively.it is noted that the value of motor phase currents increases with load impact and the frequency of current is constant because the speed is constant. Figure 5d shows the q-axis stator current, where 5e shows the daxis stator current. Figure $5 \mathrm{f}$ and $\mathrm{g}$ show $\mathrm{d}$ and $\mathrm{q}$ axis rotor currents. These results shows good load disturbance rejection of the proposed system 


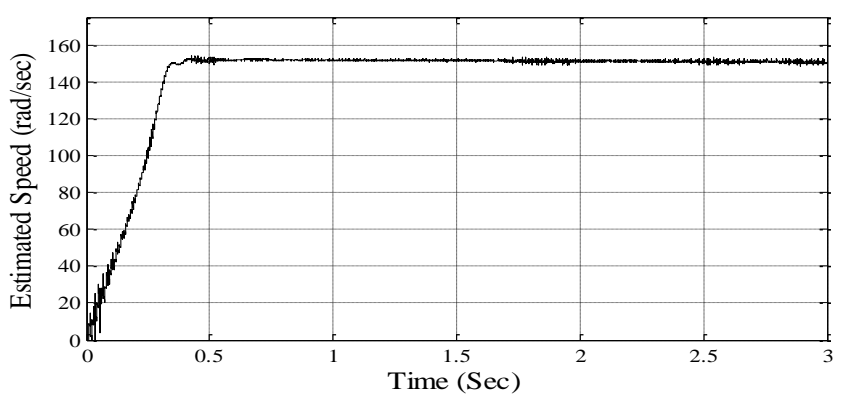

(a)

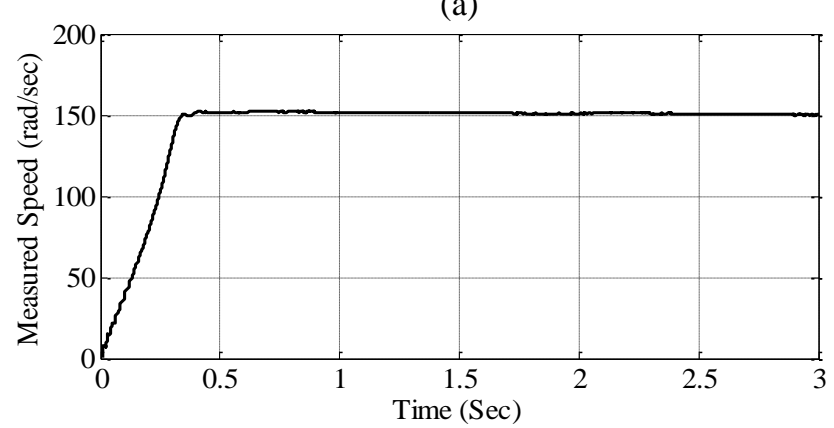

(b)
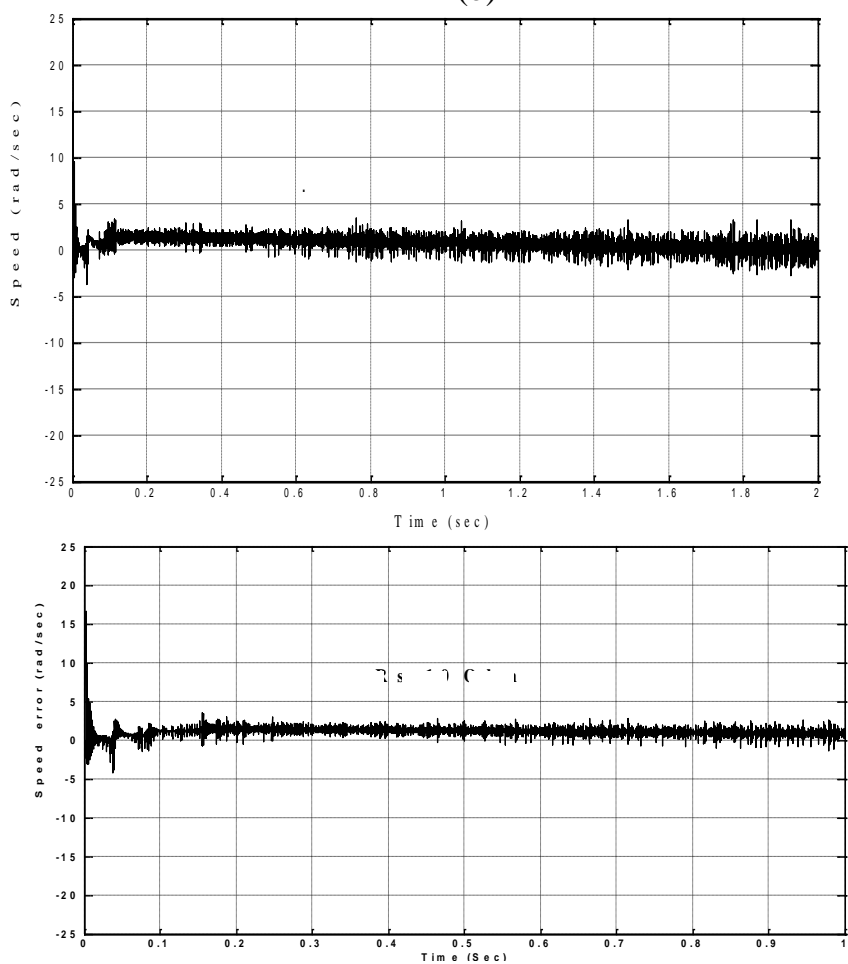

(d)

Fig. (3) Start up (a)Estimated (b) Measured speed (c) Speed error at100\% Rs (d) speed error at $135 \% \mathrm{R}$

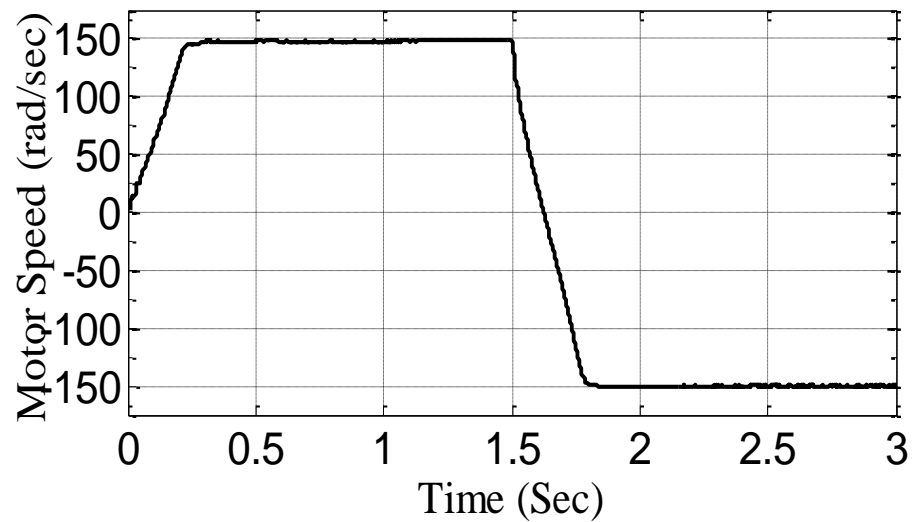

(a)

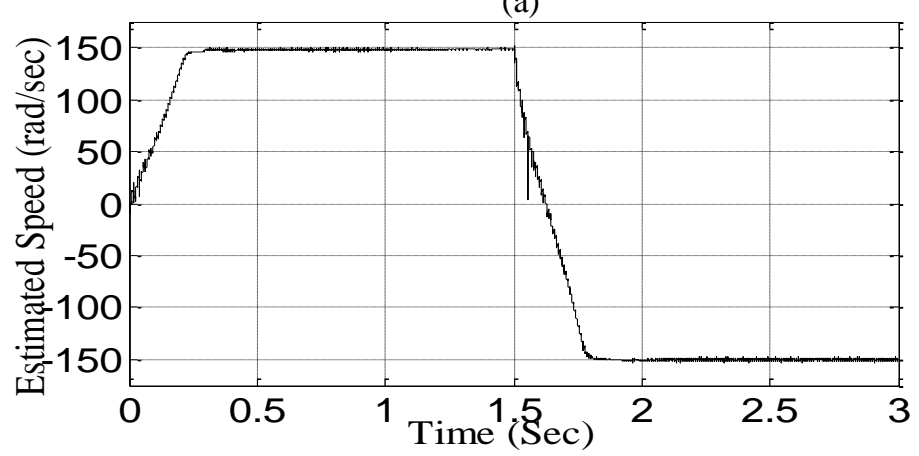

(b)

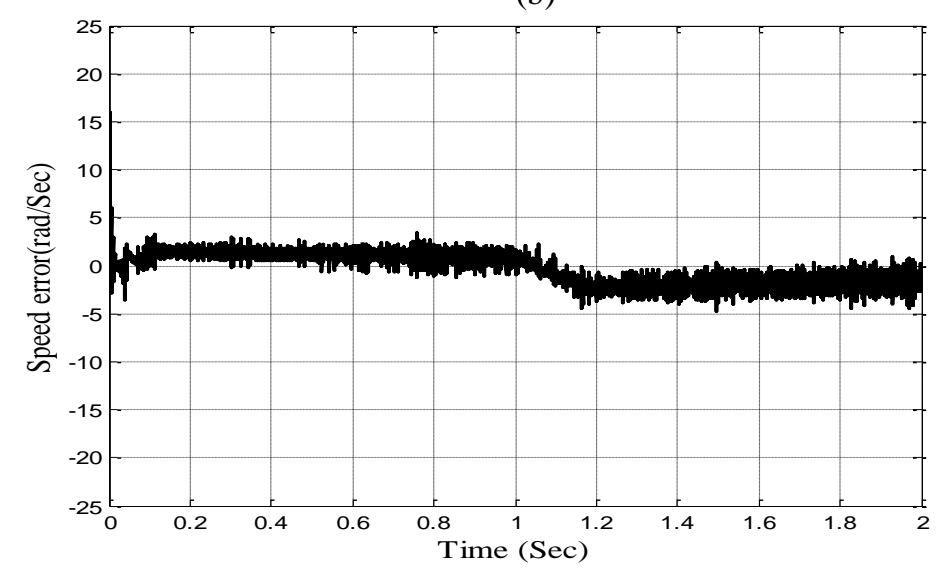

(c)

(4) Speed Reversal Estimated (b) Measured speed (c) Speed error at $100 \% \mathrm{Rs}(\mathrm{d})$ speed error at $135 \% \mathrm{Rs}$ 

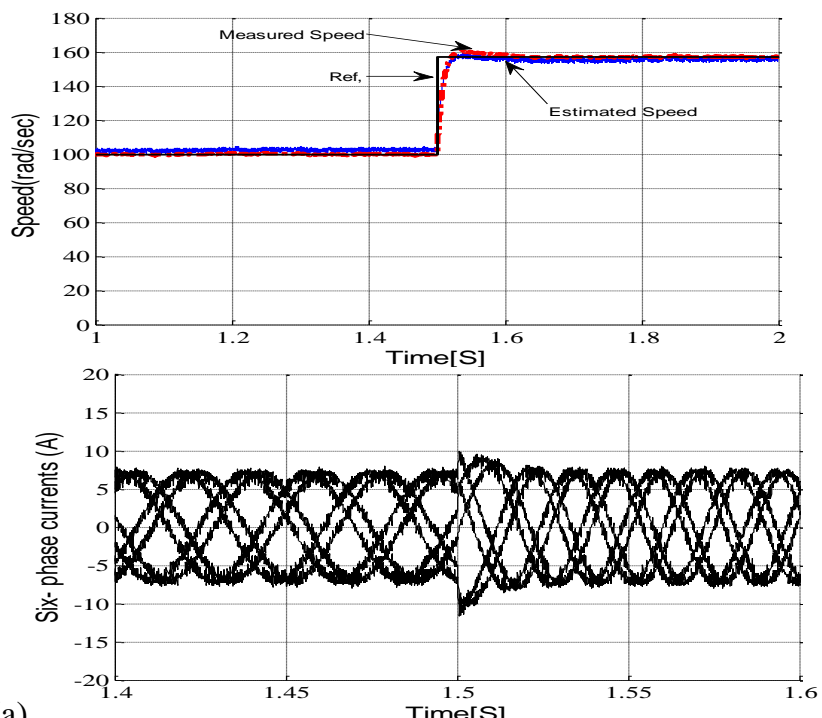

(a)

(b)

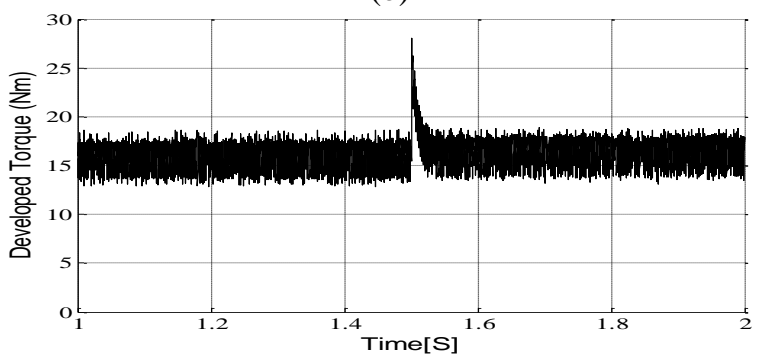

(c)

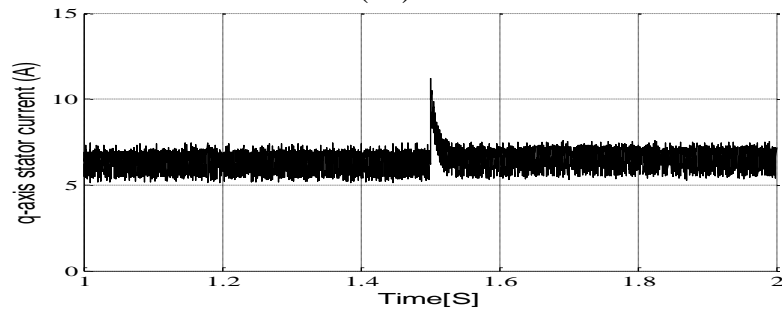

(d)

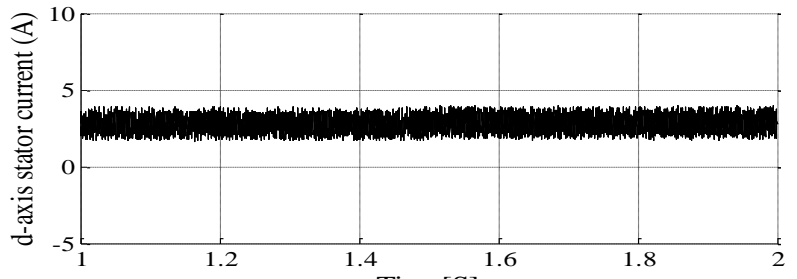

Time[S]

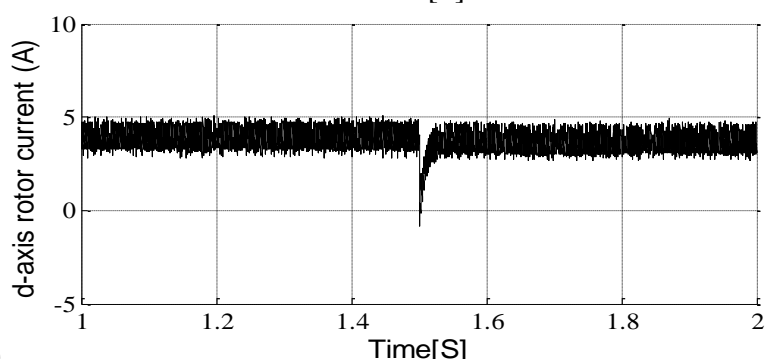

(f)

(e)

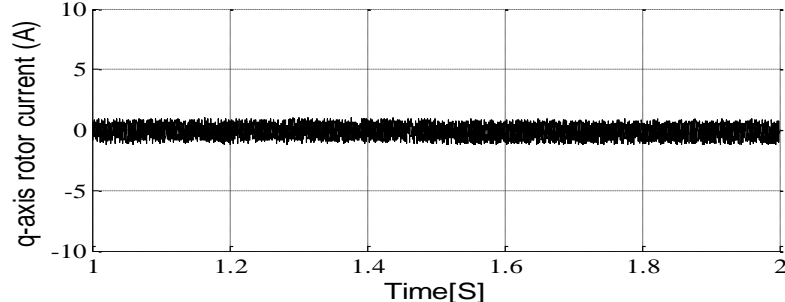

(g)

Fig. (5) Speed Step Up (100 to $157 \mathrm{rad} / \mathrm{sec}$ ) (a)Motor Speed (b) Motor Phase currents (c) Motor developed torque (d)q-axis stator current (e)d-axis stator current

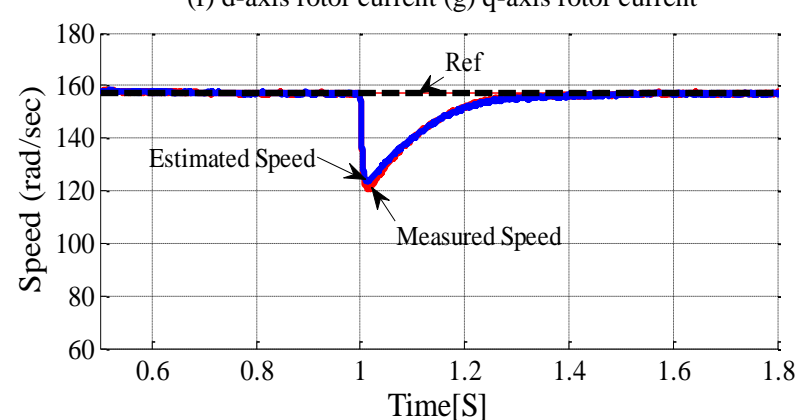

(a)

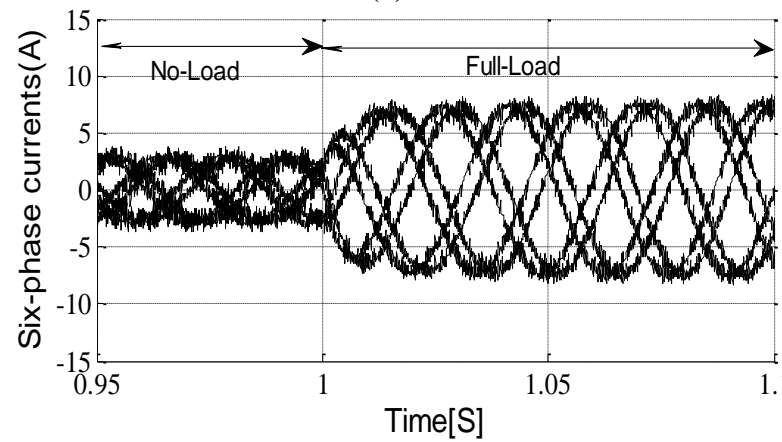

(b)

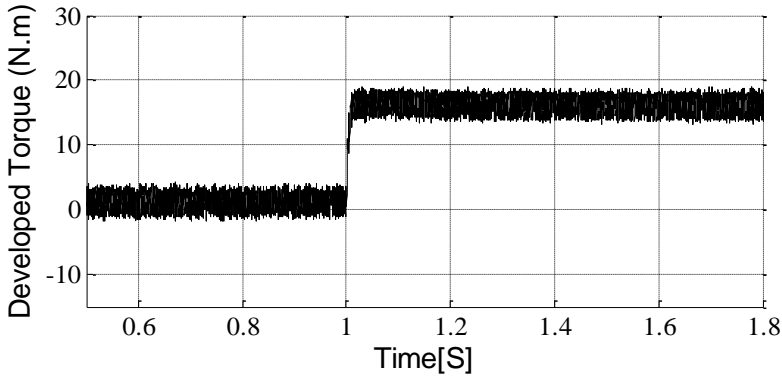

(c)

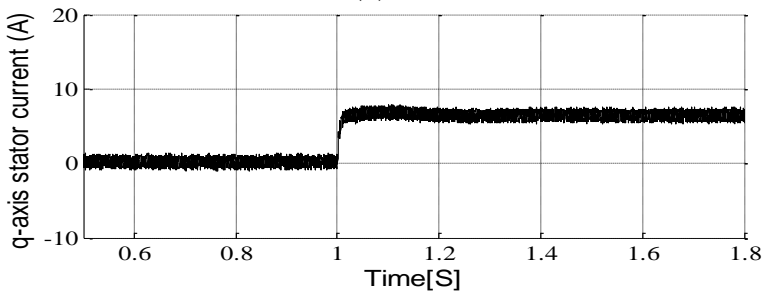

(d) 


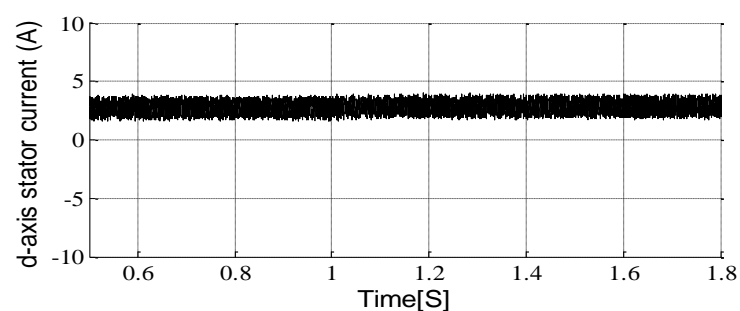

(e)

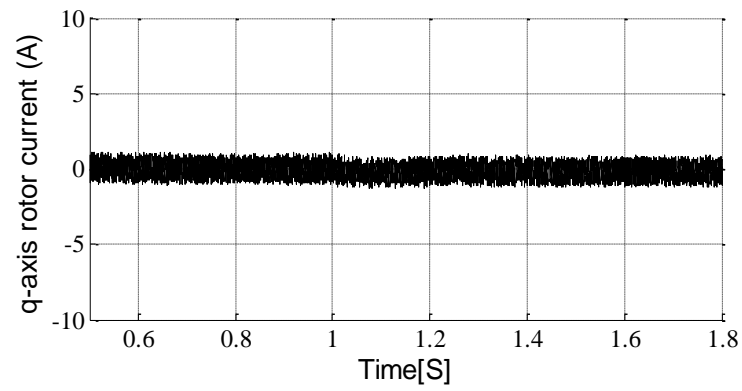

(f)

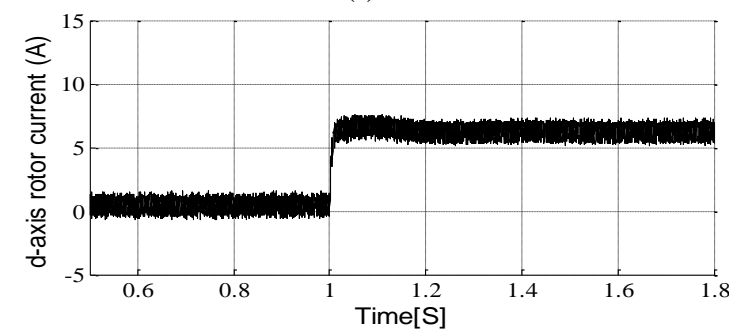

(g)

Fig. (6) Load impact (from No-load to 15N.m rad/sec) (a)Motor Speed (b) Motor Phase current (c) Motor developed torque (d)q-axis stator current (e)daxis stator current (f) d-axis rotor current (g) q-axis rotor current

\section{CONCLUSION}

This paper presents a robust rotor speed estimation method using MRAS to improve the performance of a sensorless vector controller of six-induction motor. The effectiveness of the proposed speed estimation algorithm has been investigated under dynamic and steady-state operation. A good correlation between simulated and estimated speed signals has been obtained under different operating conditions. Also, the proposed speed estimation method gives special interest since it passes the low and zero speed and preserves good speed estimation and it is robust to variations in the stator resistance. The results show the effectiveness and robustness of the proposed speed estimation procedure. As a result, the proposed method can produce an excellent speed estimation performance in a low speed region and at zero-speed

\section{References}

[1] Levi, E., Bojoi, R., Profumo, F., Toliyat, H.A., and Williamson, S., "Multiphase induction motor drives technology status review"' IEE Elec. Power appl., 2007, (in press).

[2] Singh, G.K., "Multi-phase induction machine drive research - a survey", Electric Power Systems Research, 61, pp. 139-147,2002.

[3] T. Orlowska-Kowalska and M. Dybkowski, "Robust speed-sensorless induction motor drive for traction applications," in IECON Proceedings (Industrial Electronics Conference), 2010, pp. 2358-2363.

[4] Williamson, S., and Smith, A.C., "Pulsating torque and losses in multiphase induction machines", IEEE Trans. on Industry Applications, vol. 39, no. 4, pp. 986-993, 2003.

[5] Xu, H., Toliyat, H.A., and Petersen, L.J., 'Rotor field oriented control of a six-phase induction motor with the combined fundamental and third harmonic currents', Proc. IEEE Applied Power Electronics Conference APEC, Anaheim, CA, pp. 392-398, 2001.

[6] Xu, H., Toliyat, H.A., and Petersen, L.J., 'Six-phase induction motor drives with DSP-based control system', IEEE Trans. on Power Electronics, vol. 17, no. 2, pp. 524-533,2002.

[7] Toliyat, H.A., Shi, R., Xu, H., "A DSP-based vector control of sixphase synchronous reluctance motor", Proc. IEEE IAS Annual Meeting, Rome, Italy, 2000, paper No.40_05.

[8] S. M. J. Rastegar Fatemi, N. R. Abjadi, J. Soltani, and S. Abazari, "Speed sensorless control of a six-phase induction motor drive using back stepping control," IET Power Electron., vol. 7, no. 1, pp. 114-123, 2014.

[9] J. Guzinski and H. Abu-Rub, "Speed sensorless induction motor drive with predictive current controller," IEEE Trans. Ind. Electron., vol. 60, no. 2, pp. 699-709, 2013.

[10] F. Lima, W. Kaiser, I. Nunes Da Silva, and A. A. De Oliveira, "Speed neuro-fuzzy estimator applied to sensorless induction motor control," IEEE Lat. Am. Trans., vol. 10, no. 5, pp. 2065-2073, 2012

[11] J. Maes and J. A. Melkebeek, "Speed-sensorless direct torque control of induction motors using an adaptive flux observer," IEEE Transactions on Industry Applications, vol. 36, no. 3. pp. 778-785, 2000.

[12] T. S. Kwon, M. H. Shin, and D. S. Hyun, "Speed sensorless stator fluxoriented control of induction motor in the field weakening region using Luenberger observer," IEEE Trans. Power Electron., vol. 20, no. 4, pp. 864-869, 2005.

[13] S. B. Bodkhe and M. V. B. Aware, "Speed-sensorless, adjustable-speed induction motor drive based on dc link measurement," Int. J. Phys. Sci., vol. 4, no. 4, pp. 221-232, 2009

[14] F. Alonge, F. D'Ippolito, and A. Sferlazza, "Sensorless control of induction-motor drive based on robust kalman filter and adaptive speed estimation," IEEE Trans. Ind. Electron., vol. 61, no. 3, pp. 1444-1453, 2014.

[15] T. Orlowska-Kowalska and M. Dybkowski, "Stator-current-based MRAS estimator for a wide range speed-sensorless induction-motor drive," IEEE Trans. Ind. Electron., vol. 57, no. 4, pp. 1296-1308, 2010.

[16] H. Abu-Rub, M. Rizwan Khan, A. Iqbal, and S. K. Moin Ahmed, "MRAS-based sensorless control of a five-phase induction motor drive with a predictive adaptive model," in IEEE International Symposium on Industrial Electronics, 2010, pp. 3089-3094.

[17] Y. A. Zorgani, Y. Koubaa, and M. Boussak, "Sensorless speed control with MRAS for induction motor drive," in Proceedings - 2012 20th International Conference on Electrical Machines, ICEM 2012, 2012, pp. 2259-2265.

[18] P. Santhosh, R. H. Chile, A. B. Patil, and D. R. Patil, "Model Reference Adaptive Technique for Sensorless Speed Control of Induction Motor," in 2008 First International Conference on Emerging Trends in Engineering and Technology, 2008, pp. 893-898.

[19] Chul-Woo Park, Woo-Hyen Kwon "Simple and robust speed sensorless vector control of induction motor using stator current based MRAC" Electric Power Systems Research 71, pp. 257-266, 2004.

[20] Z. M. S. El-Barbary, "Single-to-three phase induction motor sensorless drive system,” Alexandria Eng. J., vol. 51, no. 2, pp. 77-83, 2012.

[21] O. Teresa, "Adaptive sliding-mode neuro-fuzzy control of the sensorless induction motor drive with MRAS," Control, pp. 1-8, 2009.

[22] Matlab/Simulink Toolbox User's Guide, The Math works Inc., Natick, MA, USA, May 1998.

Motor Parameter

Appendix

No. of poles

4

Stator resistance

$5.66 \mathrm{ohm}$

Rotor resistance

$2.125 \mathrm{ohm}$

Rotor leakage inductance 
Recent Innovations in Mechatronics (RIiM) Vol. 4. (2017). No. 1.

DOI: $10.17667 /$ riim.2017.1/8.

Stator leakage inductance

$0.01344 \mathrm{H}$

Mutual inductance

$0.32 \mathrm{H}$

Supply frequency

$50 \mathrm{~Hz}$

Motor speed

1500 r.p.m

Supply voltage

380 volts

Inertia 0.0015 kg.m 2 